\title{
Fertility and Commuting Behaviour in Germany
}

\author{
Johannes Huinink, Michael Feldhaus
}

\begin{abstract}
Fertility behaviour is closely related to other dimensions of the individual life course, which are strongly interrelated themselves. Regarding the impact of job-related spatial mobility, empirical findings show a negative correlation between having children and commuting, particularly for women. Up to now, fertility intentions have not been thoroughly investigated in this respect. Longitudinal studies are lacking, too. In this paper, the effects of commuting arrangements of men and women on the intention of having a child within the next two years as well as the probability of realising this intention are addressed. The assumption is, that after accounting for other important factors (employment status, level of qualification, type of consensual union, number of children, residential mobility), medium- and long-distance commuting is negatively related to the fertility intention of women and its realisation. For men, effects are assumed to be nonexistent or even slightly positive. Longitudinal data from the first three waves of the German "Panel Analysis of Intimate Relationships and Family Dynamics" (pairfam) are used to test the hypotheses.

Firstly, a cross-sectional, multivariate probit-regression (with correlated errors) on the intention to have a child within two years, on being childless and on mediumand long- distance commuting is applied. The model shows no significant correlation between commuting and the intention to have a child; it does however show a correlation between medium- and long distance commuting and the probability of women to be childless. Secondly, a longitudinal difference model on changing fertility intentions between panel wave 1 and wave 3 is estimated. For women, a positive effect can be found of interrupting medium- and long-distance commuting or, surprisingly, continuing medium- and long-distance commuting on the intention to have a child within two years. Thirdly, for men and women who reported a fertility intention in the first wave, a longitudinal Heckman-selection probit-regression on the probability of having a child between wave 1 and wave 3 is estimated. It shows negative effects of medium- and long-distance commuting on having a child. Taken together, these findings support the assumption that commuting plays a characteristically different role in different phases of the fertility-related decision process.
\end{abstract}

Keywords: Spatial Mobility $\cdot$ Commuting $\cdot$ Fertility Intentions 


\section{Introduction}

Job-related spatial mobility is an important dimension of the life course and is interrelated with other life domains, such as family and work. In general, job-related mobility can be the result of or the reason for other aspects of social mobility, i.e. all kind of biographical transitions in the individual life course.

In regard to spatial mobility, two different types can be distinguished: residential and circular mobility (Schneider 2005). Residential mobility means a change of residence within a town, a move within a country or to another country. Circular mobility encompasses all kinds of transient spatial mobility. This includes daily commuting as well as other types of circular mobility, such as overnighting outside the own household for job reasons (Schneider/Meil 2008). Both types of spatial mobility, residential and circular, are interdependently linked with decisions and transitions in other life domains. They can also be interlinked with each other. For example, a move leads to a change of the distance to the workplace, if the job remains the same. Or, if the workplace changes, the question comes up whether to commute or to move (Kalter 1994).

Spatial mobility is an important factor in individual- and relationship-related life plans (Courgeau 1990). In particular, job-related mobility can be of major relevance for family development and at the same time be influenced by family planning. For example, it seems plausible to assume that job-related commuting over a long distance affects the desire to have another child and the timing of childbirth (Meil 2010a). Conversely, adapting mobility arrangements of a couple to the needs of family life can lead to a move or a change of the working place (Ku/u/Milewski 2007). Residential mobility can be a consequence or part of the process of family formation, when young parents realise that the housing situation is not an appropriate environment for their child. This again can bring about - under otherwise constant conditions - a change in job-related commuting. Therefore, spatial mobility helps to combine relationship- or family-related goals with goals in other life domains. Commuting can be an option to lower couple's decision problems and to coordinate interests of both partners (Abraham/Auspurg/Hinz 2010).

In this paper, we analyse some aspects of this complex relation between spatial mobility and family formation, respectively family extension. We analyse (1) whether even the intention of having a child within the next two years is correlated with the extent of commuting behaviour; (2) whether changes in the commuting behaviour come along with changes in regard to fertility intentions; and finally, (3) whether these have an impact on the probability of the realisation of an intended pregnancy.

The empirical basis of our study are data from the Panel Analysis of Intimate Relationships and Family Dynamics (pairfam), hereafter called the German Family Panel (Huinink et al. 2011). In this panel project, which analyses couple and family dynamics, information on spatial mobility, fertility intentions as well as other important biographical characteristics (employment, relationship) is gathered.

After presenting some relevant findings from previous research, the theoretical discussion and the deduction of the hypothesis, we will introduce the operationali- 
sation of included variables and the methods applied in our analysis. In the context of empirical analyses, we will investigate the correlation between commuting behaviour and the intention of having a child for women and men with the help of a cross sectional multiple equation model. In the second and third step, using data from the first and third wave of pairfam, the impact of changes in the commuting behaviour on the fertility intention and on the realisation of a pregnancy are analysed. In a résumé, we will summarise the findings and discuss some limitations and future research.

\section{Previous Research}

Empirical research on the relationship between fertility behaviour and spatial mobility is quite new and focuses in particular on the correlation between residential mobility and family formation (Huinink/Wagner 1989; Kulu/Milewski 2007). Although our research focus is commuting behaviour, and residential mobility is just seen as a control variable, we will take a short look at previous research about the influence of residential mobility on family formation, because both types of mobility are strongly interrelated.

After the first ground-breaking works by Rossi (1955), only a few papers regarding the relationship between family formation, local opportunity structures, and residential mobility were published in the 1980s and 1990s (comp. Hervitz 1985; Courgeau 1985, 1990; Huinink/Wagner 1989; Strohmeier 1989; Wagner 1989). In these studies, some hypotheses were developed, which are being picked up again in current research (Clark/Davies Wizers 2007; Kulu 2005; 2006; Kulu/Vikat/Andersen 2007; Kulu/Boyle 2009; Kulu/Boyle/Andersen 2009). According to these hypotheses, residential mobility brings about crucial changes in general circumstances of life, which drive plans on family formation or family extension into the background and lead to a postponement of childbearing or a decrease in fertility. In turn, having children may lead to a residential move, particular of short distance, provided that this change of residence leads to an improvement of the conditions in which to raise the first child or additional children (Kulu 2008; Rabe/Taylor 2010). Just the intention to have another child can also already trigger a move (Feijten/Mulder 2002). This is in line with previous research, showing that home ownership, particularly in combination with a marriage, coincides with the realisation of a fertility intention (Davies Wizers 1998; Mulder/Wagner 2001; Kulu/Vikat 2007).

Thus, it can be stated that there are interdependencies between residential mobility and fertility behaviour. Mobility does not only take place after the birth of a child, but often precedes an intended child birth. One can also assume - although this has not been empirically verified up to now - that residential mobility is connected to fertility intentions or a realised birth, because parents want to cut back on the burden of time-consuming commuting and not only, because they wish to improve their living environment or would like to own a house. Therefore, in order to analyse the relationship between circular mobility and fertility intentions, residential 
mobility has to be considered, too. It is important to account for residential mobility in the analysis of the relationship between commuting behaviour and fertility.

In comparison to research on the relationship between fertility behaviour and residential mobility, studies dealing with the connection between family development and commuting behaviour are considerably less frequent. Provision of adequate comprehensive and representative data is restricted. Data on commuting behaviour are made available by the German Micro Census every four years (Grau 2009). The German Socio Economic Panel (GSOEP) provides information on the commuting distance and frequency of commuting (Wagner 1989; Stutzer/Frey 2007). Huinink and Kley (Kley 2010) collected information in a three wave panel study on the commuting behaviour of residents in the cities of Magdeburg and Freiburg. Another study offers information on commuting behaviour in the Berlin-Brandenburg region (Wiethölter et al. 2009). The first larger study, which stressed the effects of circular mobility on family dynamics in Germany was conducted by Norbert Schneider (Schneider et al. 2002). This was continued in the comparative, international project "Job Mobilities and Family Lives in Europe" (JobMob) (Schneider/Meil 2008).

Schneider et al. (2002) suggested a typology of circular mobility, which has proven useful in empirical research. Besides residential mobility in regard to circular mobility, it differentiates between the amount of time needed to commute to the work place and whether people have to spend nights outside their home for job reasons. One distinguishes between: Non-mobiles (persons who are either not employed, working at home, or are employed and commute in less than 60 minutes) and long-distance commuters (LDCs; persons commuting for more than 60 minutes one way). In order to get a more fine-graded differentiation, it was suggested to distinguish the group of persons commuting in 30 to 60 minutes from the non-mobiles (Rüger et al. 2011). We call them medium-distance commuters (MDCs). Persons that have to spend more than 60 nights a year outside their home are called varimobiles. Shuttlers are people who have a second household near the workplace. Long-distance relationships (LDRs), in which both partners have their own household for job-related reasons, are also considered (Schneider et al. 2002; Limmer) Schneider 2008).

Empirical findings from cross-sectional analyses using first wave data from the JobMob project give first empirical evidence of a correlation between commuting behaviour and parenthood for men and women. If there are children in the household, then women's commuting behaviour is significantly restricted. This is not the case for men (Schneider/Meil 2008). Similar findings are reported by Kley (2010: 8): Fathers do not commute less often than childless men. However, mothers with young children in the household are more often non-mobile than other women.

Meil (2010a/b) analysed the relationship between fertility and job-related spatial mobility with JobMob-data using different indicators. Here, the subjective perception whether current childlessness is due to job-related demands was enquired. Particular mobile women (LDCs, vari-mobiles, shuttlers) agreed with this item more often than non-mobile women (39\% to $29 \%$; men: $29 \%$ to $22 \%$ ). Furthermore, mobile women emphasised more often that they were postponing the birth of a (next) child (23\% to $7 \%$; men: $11 \%$ to $7 \%$ ). The differences between mobile and 
non-mobile men are considerably lower. These results are confirmed by analysing the number of actually realised children: Women and men who were faced with higher demands of job-related mobility were childless at a significantly higher rate and had fewer children. These differences were much stronger for women compared to men. This correlation between long-distance commuting and women's fertility behaviour had already been assumed by Courgeau (1990). These empirical findings are replicated with data of the German Family Panel (pairfam). This study used the main concepts of the JobMob-project (Rüger et al. 2011). These data also show a significant interaction effect between gender and circular mobility on the probability of being childless. Women who commute medium- or long-distance are significantly more often childless (Rüger et al. 2011).

The connection between circular mobility and postponing fertility in women is also supported by non-standardised interviews (Schneider et al. 2002). Schneider et al. (2002) mention that for childless mobile women, circular mobility has the function to achieve a good financial and occupational position. These women intend to realise their desire for a child, if it is possible to reduce the exhausting long-distance commuting which is hindering parenthood. This is particular true for long-distance relationships and shuttlers. Given the fact that mothers still are more responsible for childcare and take on more of the burden of domestic work, they can meet the higher requirements of circular mobility less well. In some interviews, mothers report that they are not willing to move for job-related reasons, consider long-distance commuting or become a shuttler. Some mothers mention explicitly that they would refuse an attractive job offer, because this would undermine the interplay between family and work of both partners (Schneider et al. 2002). Thus, circular mobility is not a choice at all costs. The difficult relationship between (full-time) employment and motherhood is complemented by another important aspect: the question of how demanding a job is due to circular mobility and how compatible it is with parenthood.

In this paper, we do not primarily focus on the question of the realisation of the desire for a child, but concentrate on the connection between commuting and the intention of having a child. Fertility intention here means the wish of individuals to have a child within the next two years. Findings from motivation research show that having an intention on the one hand and realising it on the other are two interrelated, subsequent processes, which are influenced by similar but also different factors (Heckhausen 2003; Brandtstädter 2001; Ajzen/Fishbein 2005). Therefore, one has to assume that the effect of commuting on the fertility intention and its realisation is different.

Meanwhile, there are quite a considerable number of studies analysing the factors influencing fertility intentions. They show that the expected benefit and cost of a first or an additional child have a significant impact on the intention to have children (Billari et al. 2009; Philipov et al. 2006; Dommermuth et al. 2011). Internalised norms and attitudes of significant others are also relevant. The expected support provided by parents, friends or other relatives is helpful, too (Bernardi et al. 2007; Dommermuth et al. 2011). Maul et al. (2010) show that the fertility intention, measured with the intention to have a child within the next two years, depends on the 
salience (relevance/priority) of this life goal compared to other goals in other life domains. It is also relevant whether individuals believe that important prerequisites for parenthood are fulfilled (e.g. secure employment, solid relationship, adequate financial resources, childcare facilities). Similar findings were retrieved through analyses by Buhr et al. (2011): For East German women, sufficient financial resources and flexible childcare arrangements are particular predictive for the intention to have a child within the next two years. In West Germany, the compatibility of job and family is also important. Using data from the Generations- and Gender Survey, Pailhé (2009) finds that an insecure employment situation has a negative effect on the fertility intention of women. However, this effect disappears, if a woman already has a first child. Moreover, she reports a positive effect on the fertility intention, if the employer offers flexible working hours and childcare.

However, as mentioned before, the intention may not be seen on the same level as the realisation of a child. This is particular true for the general desire for a child, which again, has to be distinguished from the intention. Findings from QuesnelVallée/Morgan (2003) show, for example, that people who wish to have more than two children, overestimate the number of realised children, while those who want to have less than two children, underestimate it. This supports the assumption that the number of desired children and fertility intentions are not stable over time and that intentions must not be realised by all means. In the next section, we will try to answer the question of the role commuting behaviour plays in this context.

\section{Theoretical Considerations and Hypotheses}

From a life course perspective, spatial mobility, employment and family development are dimensions of a highly interdependent process of individual welfare production. This process can be described as a more or less coherent sequence of individual action and biographical transitions, which are influenced by subjective evaluations, aspirations, expectations, and individual motives to act in different domains of the life course. Subjectively anticipated material and non-material costs and benefits are assessed. This assessment process is influenced by the actor's subjective view on social, economical, and institutional circumstances in the short and long run, the available resources, biographical experiences, and personal traits. It comes to a decision to pursue such goals or related sub-goals, the achievement of which promises to improve or maintain the subjective well-being most efficiently (Lindenberg/Frey 1993; Huinink/Schröder 2008).

Spatial mobility, employment and raising children are different goals of the welfare production over the life course. Considering not only respective events and activities but also the decision-making process preceding them, the question of the determinants for generating goal-related intentions arises. This is the starting point of our analysis. The hypotheses, which we want to develop theoretically and test empirically, concentrate on the connection between commuting behaviour and the intention to have a child as well as the realisation of a child. Further factors which are important in the analysis of the decision in favour of parenthood and the realisa- 
tion of parenthood over the life course - such as the level of education, residential mobility, employment history - are included in our empirical analysis as control variables, but not discussed in detail.

In our account of previous research, we reported that individuals with a higher demand for mobility are more often childless. This is particularly true for women. Now, the question arises whether this correlation can already be found in the fertility-related decision process, more precisely, whether the correlation already arises when looking at the fertility intention or whether it is only correlated with its realisation.

At least two main strands of arguments can be distinguished. The first strand of argument supports what we call the resource argument. According to findings in the context of a qualitative analysis in an earlier study conducted by Schneider et al. (2002), for women, commuting is one way to achieve the pursued occupational and financial basis, which allows her to realise a given desire for a child. This would mean that women with more demanding commuting arrangements more often show an intention to have child than those who do not commute or whose commuting time is short. The burden of more demanding commuting is taken on in order to fulfil the prerequisites (financial and occupational security) for becoming a parent. The mobility arrangement, which might be intended as temporary, would be an instrumental sub-goal for attaining family-related subjective well-being. Mobility can be perceived as an indicator for occupational success, which in turn should be supportive of a fertility intention and its realisation (Buhr et al. 2011). To achieve both, occupational success as well as family formation and family life, people rather commute for longer distances than taking a second residence for job reasons.

The second line of argument addresses the compatibility argument. It is argued that a high demand for job-related mobility hinders the compatibility of family and work. Even without commuting, combining family and work can already be a difficult task. Thus, costly mobility arrangements should correlate negatively with the opportunities of organising parental tasks. This should be in particular true for those individuals who are responsible for childcare, which still applies more for women than for men (Geis/er/Kreyenfeld 2006; Wengler/Trappe/Schmitt 2008). Therefore, one can assume that particularly women who commute longer distances postpone the realisation of a family. These women do not only have less children or stay childless, but also do not even have the intention (at least in the short-run). We expect that an intention or plan to have children only occurs when they reduce the burden of mobility.

Particularly for women who need to work for financial reasons, who have got limited alternatives regarding the kind of job they are employed in, or who have problems returning to their workplace after childbirth, for those, problems in combining family and work can be an obstacle to plan a pregnancy in the short-run. The life goals of an occupational career and family are competitive. While spatial mobility can be a crucial requirement for achieving a job-related goal, it simultaneously can be detrimental for the realisation of a fertility intention. This is often postponed, until a reduction of commuting occurs. Only if commuting is given up, it comes to an intention and to a realisation of a pregnancy. 
It is difficult to say which argument has more weight. Previous findings show that the question of compatibility of family and work is more relevant than the resource-related argument, when it comes to the realisation of a fertility intention. Especially women with more demanding mobility arrangements (such as mediumor long-distance commuting) should have weaker fertility intentions compared to those with less demanding arrangements, due to problems with the compatibility of work and family. This expected effect could be less pronounced regarding the intention than regarding the realisation of a pregnancy. Whereas a fertility intention can go along with an intention to change the mobility arrangement first, in order to achieve the requirements of compatibility, the latter intention might not be realised and childbirth will be postponed unintendedly. For men, we assume no or even small positive effects of commuting on family formation, i.e. we assume that the resource argument should be more relevant.

In addition to the resource- and the compatibility argument, effects of self-selection have to be considered. Those individuals who do not want to have any children are more willing to take on higher job-related mobility. This results in a negative correlation between fertility intentions and more demanding commuting, which is based on plans for life formed earlier in the life course (Schröder/Brüder/ 2008). In order to handle this problem, it is necessary to use panel data, which allow accounting for such selection effects. According to our previous arguments, we have formulated the first two hypothesis, hereby differentiating between a cross sectional and a longitudinal perspective:

1. In a cross sectional analysis, time-consuming commuting of women is negatively correlated with the probability of the intention to have children and the realisation of a pregnancy. This effect does not appear among men, or should even be positive.

2. In the longitudinal perspective, reducing commuting distances increases the probability of the fertility intention among women and vice versa. For men, this is not the case, or the other way around.

Having an intention to achieve a certain goal does not guarantee that the goal is actually achieved (Ajzen/Fishbein 2005). Unexpected factors as well as a wrong perception of the life situation can be hindering or supportive for a pursuit of a goal. The overestimation of the behavioural control or self-efficacy can cause a discrepancy between intention and behaviour. In our discussion of previous research, we showed that this could also be true in the case of fertility intentions (Meil 2010a/b). There is also empirical evidence that demanding commuting arrangements produce stress and health problems, which might have negative effects on the fertility intention, too (Schneider et al. 2002). Therefore, we assume that a demanding commuting arrangement is one of the factors, which might be perceived as a strong obstacle for transition to parenthood, only when couples want to realise their intention, and that it leads to a postponement of a planned child. This brings us to our third hypothesis: 
3. In the longitudinal perspective, the probability of realising a pregnancy by women who intend to have a child is negatively correlated with commuting distances. For men, no or moderately positive effects should be found.

\section{Data and Operationalisation}

\subsection{Data}

In the following analyses we use data from the „Panel Analysis of Intimate Relationships and Family Dynamics" (pairfam). This is a representative, interdisciplinary, longitudinal study of intimate relationships and familial living arrangements in Germany, which collects data every year (Huinink et al. 2011; Nauck 2012). In our analysis, we include the respondents (anchors), who were between 25 and 27 or 35 and 37 years old at the time of the first panel wave in 2008/09.

In the first and third wave of pairfam, important information on job-related spatial mobility was collected in order to get the best possible picture of the couples' and families' organisation of everyday life. Therefore, pairfam also allows analysing job-related spatial mobility as such as well as its circumstances and consequences using a prospective cohort design. Because of the huge level of information being gathered in this panel and restricted survey time, detailed data on mobility are only collected in every second wave. In the other waves, a reduced number of questions are asked every year. As we use data from the first and third wave of the pairfampanel, we are able to analyse effects of spatial mobility and its changes between these waves on childbirth and on the change of fertility intentions. Pairfam provides the opportunity to distinguish between living arrangements and mobility as well as multi-locality patterns in greater detail. In addition, information on couples' dynamics and intentions, such as the intention to have a first child, can be retrieved over a long period of time. Besides relevant cross sectional data from the first wave changes in the activity status, the number of children, the place of residence and the mobility patterns are of particular interest for the longitudinal analysis.

\subsection{Operationalisation of the Variables and Strategy of the Data Analysis}

\section{Commuting Behaviour}

For the definition and classification of types of job-related commuting and multilocality, we differentiate between the various patterns following the work of Schneider et al. (Schneider et al. 2002; Schneider/Meil 2008; Limmer/Schneider 2008; Rüger et al. 2011): We distinguish between medium- and long-distance commuters 
on the one hand and short-distance commuters (reference category) on the other. ${ }^{1}$ The short-distance commuters need less than 30 minutes (one way), the mediumdistance commuters need at least 30 minutes but less than 60 minutes, and longdistance commuters travel 60 minutes and more.

\section{Fertility Intention}

The fertility intention is measured with the question, whether the respondent intended to have a child within the next two years. The variable used to measure the intention is coded dichotomously, even though there are four options for the answer. When respondents answered "do not know" or "have not thought about it yet" we assume that they do not intend to have a child within the next two years.

If respondents had stated earlier in the interview that they did not expect to have more children or did not think about having children, this question was not asked. In these cases, we also assumed no intention. The question did not apply to pregnant respondents, either. They were excluded from the analysis. In the first wave of pairfam, this question was not asked if respondents reported that they or their partner was not able to have children or that they were homosexual. These cases were also excluded from the analysis, even though we are aware of the fact that many homosexual respondents may want to have children.

\section{Conception}

Not the birth of the child but the conception is our indicator for the realisation of a fertility intention. In this way, we avoid interpreting a change in the commuting behaviour occurring after conception as a causal reason for childbirth. The time of conception is reconstructed by using the information about the date of birth of a child or about the fact that a respondent (or his partner) is pregnant at the time of the interview in the third wave. In the first case, we subtract 9 months from the date of birth. Therefore, pregnancies, which were not successful, are not considered. In the second case, we assume that conception took place approximately 4 months before the date of the interview of the third wave.

\section{Control Variables}

We have included a number of control variables. These are an indicator of the respective respondent's age group (25-27 or 35-37 years); a dichotomous indicator of the level of qualification, i.e. whether the respondent has graduated from a (technical) university or not; and information on the labour force participation. Regarding the latter, we distinguish between full-time employment or self-employment, part-

1 The so-called „vari-mobiles" are assigned to the respective commuter-categories. "Shuttlers" with a job-related second household were excluded from the analysis, because the sample size was too small. 
time employment and non- or unemployment. As to the partner, we included an indicator of occupational status, i.e. whether the partner is an entrepreneur with employees or working as professional, in upper level service sector positions or in leading managerial positions in the private sector.

To characterise the relationship constellation, we distinguish whether the couples lived in one common household or not. We also considered the number of children and include an indicator of the salience of a (or another) child. It is a measure of the importance, which at the time of interview a respondent attributed to a first or another child compared to the commitment in work and education, leisure and hobbies, friends or a relationship (Maul/Huinink/Schröder 2010; Brüderl et al. 2010). As we assume that mobility is correlated with the size of the city the respondents lived in, we included one more indicator. It indicates whether the respondents live in a place with up to 5000 inhabitants (small town) or in a big city with 500.000 inhabitants and more, places with a size in-between being the reference category. Finally, we included the information whether the respondents live in East or West Germany at the date of the first wave's interview.

\section{Models and Methods of Analysis}

In addition to some descriptive information, we analysed the proposed interdependencies in three steps applying probit-regressions for men and women separately.

In a first step, we estimated a multivariate probit regression model with correlated errors in a cross-sectional analysis (hypothesis 1) using the data of the first wave of the panel. It allowed us to obtain unbiased estimates of the correlation between commuting behaviour and the fertility intention respective to childlessness (Cappellari/Jenkins 2003). The dependent variables are the fertility intention, reported childlessness and medium- and long-distance commuting of the respondents. The latter two dependent variables are also predictors of the first one, and the indicator of medium- and long-distance commuting is modelled as a predictor of childlessness. Effects of common unobserved sources of a correlation between fertility intention, reported childlessness and commuting behaviour are accounted for in the multivariate model. The equations with fertility intention and childlessness as dependent variables allowed us to test for the expectation of different effects of commuting on intention and realisation of fertility.

Because of technical reasons in our cross-sectional analysis, we included only respondents who were employed at the time of the interview of the first wave. If we had included the non-employed respondents, the third equation of the model could not be identified because, by definition, non- or unemployed persons do no commute for job reasons. We also included only those respondents who had a partner not in education and not pregnant at the time. In Table 1, the sample size and information on the distribution of the variables, which have been included in the first model, are displayed.

In the second step, we estimated the effect of a change in the commuting scheme on a change in the fertility intention between the first and the third wave in a difference-model (Allison 2009). Here, the dependent variable is an indicator expressing 
Tab. 1: Distribution of the dependent and independent variables in the crosssectional multi-equation model; men and women (percentages)

\begin{tabular}{lcc}
\hline & Men & Women \\
& $\mathrm{N}=1572$ & $\mathrm{~N}=1679$ \\
\hline Fertility intention reported & 34.5 & 33.0 \\
Childless & 37.7 & 38.9 \\
One child & 23.5 & 24.2 \\
Long-distance commuter & 9.3 & 5.5 \\
Medium-distance commuter & 23.7 & 20.4 \\
(Technical) university degree & 22.9 & 23.8 \\
Full-time or self-employment & 95.6 & 51.2 \\
High occupational status of partner & 8.0 & 25.0 \\
Cohabiting & 86.1 & 83.1 \\
Older age group & 64.8 & 58.5 \\
Living in West Germany & 81.2 & 80.0 \\
Living in a small town & 17.8 & 17.3 \\
Living in a big city & 9.1 & 9.1 \\
Salience of childbirth (mean) & 1.76 & 1.65 \\
\hline
\end{tabular}

Source: pairfam wave1; own calculations

what kind of change in the intention between the two waves was observed. One can see a switch from a reported intention in the first wave to no intention in the second wave and vice versa. The difference-model controls for time-constant unobserved heterogeneity of the respondents.

In addition, information about changes or events in other life domains is included in the model: the occurrence of a pregnancy, a change in the employment status, short-distance residential mobility (distance of less than $50 \mathrm{~km}$ ) and long-distance residential mobility (distance of $50 \mathrm{~km}$ and more). Medium- and long-distance commuters were assembled into one category as the size of the sample used in this model is small. It can be assumed that this is not a problem, because in the crosssectional models we found that their effects go in the same direction. In the model, we distinguished between respondents who did not commute these distances over the whole period of time (reference group), those who did commute medium- and long-distance over the whole period of time, and those who changed their commuting behaviour in one direction or the other. We also included time-constant variables (e.g. age group, living in West Germany), the coefficients of which express whether the effect of these variables on the fertility intention changed between wave 1 and 3.

In the difference model, all cases were excluded that did not experience a change in the fertility intention between wave 1 and 3 . Again, we restricted our sample by including only those respondents who had a partner not in education and not preg- 
Tab. 2: Distribution of the dependent and independent variables included in the difference-model; men and women (percentages)

\begin{tabular}{lrr}
\hline & $\begin{array}{c}\text { Men } \\
\text { N=209 }\end{array}$ & Women \\
& & \\
& & \\
\hline Time dependent variables (changes between wave 1 and 3) & \\
Fertility intention: & 34.5 & 32.3 \\
$\quad$ switch from no to yes & 65.5 & 67.7 \\
$\quad$ switch from yes to no & 8.6 & 8.5 \\
Commencement of medium-/long-distance commuting & 22.5 & 11.2 \\
Constantly commuting medium-/long-distance & 9.1 & 8.9 \\
Medium-/long-distance commuting ended & 4.3 & 11.9 \\
Switch from full-time to non-employment & 0.5 & 3.1 \\
Switch from full-time to part-time employment & 2.4 & 20.4 \\
Part-time employment unchanged or switch from non- to part-time & & \\
employment & 6.2 & 33.5 \\
Constantly non-employed or switch from part-time to non- & 24.4 & 25.4 \\
employment & 2.9 & 4.2 \\
Short-distance move (< 50 km) & 11.5 & 11.5 \\
Long-distance move ( $\geq 50$ km) & 37.3 & 43.5 \\
Moved in with partner & & \\
Occurring pregnancy between W1 und W3 & 11.5 & 24.2 \\
Time-constant variables at wave 1 & 81.3 & 81.9 \\
High occupational status of partner & 55.0 & 35.4 \\
Living in West Germany & 2.35 & 2.63 \\
Older age group & & \\
Salience of childbirth (mean) & & \\
\hline
\end{tabular}

Source: pairfam waves 1 and 3; own calculations

nant at wave 1. Additionally, we considered only those respondents who lived with the same partner during the whole observation period. In this case, we allowed non- and unemployment in the first wave in order to keep those persons in the analysis who started commuting after they had gotten a job. To account for effects of changes in the employment status, indicators of those changes between wave 1 and 3 were included in the model. In Table 2, the descriptives of the variables considered in the difference-model are shown.

In the third step of analysis, we estimated the probability of a pregnancy (until wave 3) among respondents who in the first wave reported an intention to have a child within the next two years. Here, we included all respondents independently from their employment status but living with the same partner over the time period between wave 1 and 3 . In order to control the sample selection, we applied a probitregression with a Heckman correction (Dubin/Rivers 1990). Predictors are - similar 
Tab. 3: Distribution of the variables included in the model of the realisation of a pregnancy; for men and women (percentages)

\begin{tabular}{lrr}
\hline & Men & Women \\
& $\mathrm{N}=303$ & $\mathrm{~N}=376$ \\
\hline Time-dependent variables (changes between wave 1 and 3) & 36.6 & 38.0 \\
Became pregnant & 6.6 & 10.1 \\
Commencement of medium-/long-distance commuting & 23.4 & 12.5 \\
Constantly commuting medium-/long-distance & 6.9 & 7.5 \\
Medium-/long-distance commuting ended & 1.0 & 1.9 \\
Switch from full-time to non-employment & 0.7 & 3.7 \\
Switch from full-time to part-time employment & & \\
Part-time employment unchanged or switch from non-to part-time & 1.7 & 26.3 \\
employment & 3.0 & 18.4 \\
Constantly non-employed or switch from part-time to non-employment & 12.9 & 14.1 \\
Short-distance move (< 50 km) & 2.3 & 2.9 \\
Long-distance move ( $\geq 50$ km) & & \\
Time-constant variables at wave 1 & & \\
Childless & 51.8 & 47.9 \\
Having got one child & 33.7 & 35.9 \\
(Technical) university degree & 27.1 & 29.8 \\
Cohabiting & 86.8 & 86.7 \\
High occupational status of partner & 8.3 & 27.9 \\
Older age group & 60.1 & 37.2 \\
Living in West Germany & 80.9 & 80.6 \\
Salience of childbirth (mean) & 2.85 & 2.86 \\
\hline
\end{tabular}

Source: pairfam waves 1 and 3; own calculations

to the difference model - changes in the commuting arrangements and the employment status as well as residential mobility taking place before a potential pregnancy or the date of the interview in wave $3 .^{2}$ Because of the small sample size, we put all men with the employment status full-time or self-employed over the whole period of time into one category and those who were not (i.e. who left full-time or part-time employment, who worked in part-time employment over the whole period of time or had been constantly non- or unemployed) into another category. In Table 3 descriptives of the variables are displayed.

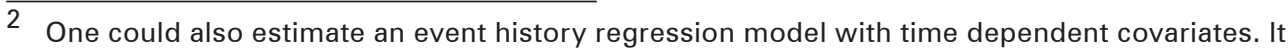
should provide similar results. 


\section{$5 \quad$ Findings}

We will now present the empirical findings following the three steps of analysis and test the hypotheses we formulated in chapter 3.

\section{First Hypothesis}

In the first hypothesis, we proposed a negative relationship between the fertility intention and extensive commuting for women, not so for men. We analysed in the first cross-sectional regression model whether this correlation can be found after accounting for other factors, which might be predictive for a fertility intention. We estimated a recursive, multivariate probit-regression with correlated errors, for women and men separately. Negative (positive) coefficients mean a negative (positive) correlation of the independent variable with the probability of the considered status in one of the dependent variables. Included are men and women of the age groups 25-27 and 35-37, who or whose partner was not pregnant, had a partner and had finished education at the time of the survey. We first estimated the same model for men and women separately. In a second model, we additionally included an interaction effect between employment status and the kind of commuting on the fertility intention. As this has shown not significant for men, it is only displayed for women. Results are displayed in table 4.

The most important finding for men and women in model 1 is that commuting distance does not play a considerable role for the fertility intention. In regard to women, this was not expected. The finding seems to show that the question of compatibility is less crucial than assumed. In the model including the interaction of the employment status (full-time/self-employed) with commuting behaviour, it can be seen that women working part-time and commuting long distances show a significantly lower probability of the intention to have a child within the next two years than full-time employed women (comp. the main effect of long-distance commuting in model 2). If the main effects and the interaction effect of long-distance commuting and full-time employment are considered, it becomes apparent that longdistance commuting and full-time employed women do not differ from full-time employment women who commute short-distance. Descriptive analyses support the assumption that the household of part-time employed women are less well-off economically than their full-time employed counterparts. For them, the economic pre-conditions for having a child are possibly not fulfilled sufficiently. This supports the assumption that the resource-argument is of some relevance.

The coefficients of the control variables in the equation of the fertility intention are mainly as one would expect. Men without children or with one child, who cohabit, and who show a high salience of having a(nother) child, have high fertility intentions. For women, the level of education ((technical) university degree) is positively significant, which can be interpreted as supporting the resource argument. Furthermore, women with no or one child and women with a high salience for (further) fertility intend to have a(nother) child within the next two years with a significantly 
Tab. 4: Mulitvariate probit-regression on the probability of a fertility intention, childlessness and medium-/long-distance commuting (recursive multivariate model with correlated errors)

\begin{tabular}{|c|c|c|c|c|c|c|}
\hline & \multicolumn{2}{|c|}{ Men } & \multicolumn{4}{|c|}{ Women } \\
\hline & Coeff. & Sig.-Lev. & Coeff. & $\begin{array}{l}\text { Model } 1 \\
\text { Sig.-Lev. }\end{array}$ & Coeff. & $\begin{array}{l}\text { Model } 2 \\
\text { Sig.-Lev. }\end{array}$ \\
\hline \multicolumn{7}{|l|}{ DV: Fertility intention } \\
\hline Long-distance commuting (LDC) & 0.05 & 0.83 & -0.25 & 0.29 & -0.96 & $0.02^{* *}$ \\
\hline $\begin{array}{l}\text { Medium-distance commuting (MDC) } \\
\text { (Ref.: short distance) }\end{array}$ & -0.17 & 0.37 & -0.20 & 0.33 & -0.24 & 0.31 \\
\hline No child & 1.12 & $0.00 * * *$ & 1.00 & $0.00 * * *$ & 1.01 & $0.00 * * *$ \\
\hline $\begin{array}{l}\text { One child } \\
\text { (Ref.: more than one child) }\end{array}$ & 0.97 & $0.00 * * *$ & 0.73 & $0.00 * * *$ & 0.73 & $0.00 * * *$ \\
\hline (Technical) university degree & 0.14 & 0.12 & 0.19 & $0.04^{* *}$ & 0.19 & $0.04 * *$ \\
\hline Cohabiting & 0.24 & $0.08^{*}$ & 0.14 & 0.20 & 0.13 & 0.20 \\
\hline High occupational status of partner & -0.10 & 0.51 & 0.13 & 0.14 & 0.13 & 0.13 \\
\hline $\begin{array}{l}\text { Full-time/self-employed (FS) } \\
\text { (Ref.: part-time employed) }\end{array}$ & 0.33 & $0.07 *$ & 0.19 & 0.16 & 0.14 & 0.34 \\
\hline Older age group & -0.05 & 0.65 & -0.46 & $0.00 * * *$ & -0.45 & $0.00 * * *$ \\
\hline Living in West Germany & 0.06 & 0.51 & -0.04 & 0.72 & -0.05 & 0.68 \\
\hline Interaction LDS * FS & & & & & 0.88 & $0.03 * *$ \\
\hline Interaction MDC * FS & & & & & 0.05 & 0.80 \\
\hline Salience of childbirth & 0.31 & $0.00 * * *$ & 0.29 & $0.00 * * *$ & 0.29 & $0.00 * * *$ \\
\hline Constant & -2.16 & $0.00 * * *$ & -0.69 & $0.09 *$ & -0.68 & $0.09 *$ \\
\hline DV: Childless & & & & & Comp. $v$ & women, Model \\
\hline Long-distance commuting (LDC) & -0.07 & 0.75 & 0.56 & $0.02 * *$ & & \\
\hline $\begin{array}{l}\text { Medium-distance commuting (MDC) } \\
\text { (Ref.: short distance or no commuting) }\end{array}$ & -0.19 & 0.31 & 0.48 & $0.01 * * *$ & & \\
\hline (Technical) university degree & 0.05 & 0.61 & 0.41 & $0.00 * * *$ & & \\
\hline Cohabiting & -1.39 & $0.00 * * *$ & -0.67 & $0.00 * * *$ & & \\
\hline High occupational status of partner & 1.21 & $0.00 * * *$ & 0.01 & 0.90 & & \\
\hline $\begin{array}{l}\text { Full-time/self-employed (FS) } \\
\text { (Ref.: part-time employed) }\end{array}$ & 0.15 & 0.41 & 1.51 & $0.00 * * *$ & & \\
\hline Older age group & -1.15 & $0.00 * * *$ & -1.48 & $0.00 * * *$ & & \\
\hline Living in West Germany & 0.25 & $0.01 * * *$ & 0.73 & $0.00 * * *$ & & \\
\hline Constant & 3.50 & $0.00^{* * *}$ & 2.33 & $0.00 * * *$ & & \\
\hline DV: Medium-/long-distance commuting & & & & & Comp. & women, Model \\
\hline (Technical) university degree & 0.13 & 0.11 & 0.28 & $0.00 * * *$ & & \\
\hline Cohabiting & 0.01 & 0.91 & 0.03 & 0.73 & & \\
\hline High occupational status of partner & -0.16 & 0.19 & 0.04 & 0.61 & & \\
\hline $\begin{array}{l}\text { Full-time/self-employed (FS) } \\
\text { (Ref.: part-time employed) }\end{array}$ & 0.20 & 0.24 & 0.18 & $0.01 * * *$ & & \\
\hline Older age group & 0.05 & 0.50 & -0.18 & $0.01 * * *$ & & \\
\hline Living in West Germany & -0.09 & 0.32 & -0.17 & $0.04^{* *}$ & & \\
\hline Living in a small town & 0.01 & 0.94 & -0.11 & 0.25 & & \\
\hline $\begin{array}{l}\text { Living in a big city } \\
\text { (Ref.: .: Living in medium size city) }\end{array}$ & 0.48 & $0.00 * * *$ & 0.49 & $0.00 * * *$ & & \\
\hline Constant & -0.77 & $0.00 * * *$ & -0.28 & 0.21 & & \\
\hline Number of cases & 1.572 & & 1.679 & & 1.679 & \\
\hline LR $\operatorname{chi}^{2}(27)$ & 783.41 & & 1070.64 & 0.00 & 1076.59 & 0.00 \\
\hline $\begin{array}{l}\text { Test of rho } 21=\text { rho31 }=\text { rho32 }=0 \\
\text { chi }^{2}(3) ; \text { Sig. }\end{array}$ & 1.35 & 0.72 & 2.27 & 0.52 & 2.41 & 0.49 \\
\hline
\end{tabular}

${ }^{* * *}$ sig. at level 0,$01 ;{ }^{* *}$ sig. at level 0,$05 ;{ }^{*}$ sig. at level 0,10

Source: pairfam, wave 1 
higher probability. We see a negative age effect, meaning that the fertility intention is weaker in the older age group.

The findings in the equations estimating the probability of childlessness and medium-/long-distance commuting are also in accordance to what one would expect. However, with one exception, we will not comment on them in detail. Commuting behaviour is a strong predictor of the probability of childlessness for women. As we found virtually no correlation between time-consuming commuting and the fertility intention, childlessness is strongly and negatively correlated with it. This reinforces findings of previous research. All models seem to be well-specified and the effects of endogeneity seem to be small because the errors of the equations are not correlated significantly with each other.

\section{Second hypothesis}

The second hypothesis proposes that a change in the commuting arrangement should induce a change of the fertility intention - even though we cannot rule out that there is also an effect in the reverse direction. The commencement of mediumor long-distance commuting should trigger giving up such an intention and terminating commuting should foster it. As additional events, we consider changes in the employment status, residential mobility, and a change in regard to the cohabitation with a partner. In the difference model, the dependent variable expresses whether a respondent gives up a fertility intention or develops it between wave 1 and wave 3 . The reference category in our model is giving up the intention. As cases with a constant intention are excluded from the analysis, we do not analyse whether a change or no change in the commuting arrangement have effects on the stability of the fertility intention. ${ }^{3}$ Mainly, in this analysis, we consider the independent variables of the previous model, but focus on time dependent attributes. Because of small sample size, we put medium- and long-distance commuters into one category, as their effects show the same direction anyway. The results are displayed in table 5.

It is not surprising that we did not find a negative effect of the commencement of time-consuming commuting on the fertility intention of women. This is in accordance with the results of the first analysis. If women gave up medium- or long-distance commuting between wave 1 and wave 3, however, they reported an intention in the third wave more frequently compared to those who were constantly immobile or short-distance commuters. The coefficient is nearly significant at the 10 per cent level. This can be interpreted differently. Either it could mean that giving up commuting leads to a consideration of having a child, as we assumed. However, it could also mean that the intention to have a child triggers a discontinuation of time-consuming commuting. As we do not have empirical information on the chronological order of these changes, we cannot decide which version is correct.

3 To do this in separate models, for respondents with or without a fertility intention at wave 1, we can estimate the probability of a change and control for sample selection using the Heckmancorrection. 
Tab. 5: Probit-regression on the probability of developing or giving up a fertility intention between wave 1 and 3 (difference-model)

\begin{tabular}{|c|c|c|c|c|}
\hline & \multicolumn{2}{|c|}{ Men } & \multicolumn{2}{|c|}{ Women } \\
\hline & Coeff. & Sig.-Lev. & Coeff. & Sig.-Lev. \\
\hline \multicolumn{5}{|l|}{ Time-dependent variables } \\
\hline Commencement of medium-/long-distance & & & & \\
\hline Commuting & -0.14 & 0.76 & 0.11 & 0.75 \\
\hline Constantly commuting medium-/long-distance & 0.03 & 0.90 & 0.79 & $0.01 * * *$ \\
\hline $\begin{array}{l}\text { Medium-/long-distance commuting ended } \\
\text { (Ref.: Continuous/y short distance) }\end{array}$ & -0.56 & 0.21 & 0.51 & 0.14 \\
\hline Switch from full-time to non-employment & 0.25 & 0.61 & 0.47 & 0.37 \\
\hline Switch from full-time to part-time employment & & & -0.20 & 0.61 \\
\hline $\begin{array}{l}\text { Part-time employment unchanged or switch from } \\
\text { non- to part-time employment }\end{array}$ & 0.71 & 0.32 & 0.08 & 0.76 \\
\hline $\begin{array}{l}\text { Constantly non-employed or switch from part- } \\
\text { time to non-employment } \\
\text { (Ref.: Switch to or continuously full-time/self- } \\
\text { employed) }\end{array}$ & 0.33 & 0.44 & -0.17 & 0.51 \\
\hline Short-distance move $(<50 \mathrm{~km})$ & 0.37 & 0.15 & 0.12 & 0.59 \\
\hline Long-distance move ( $\geq 50 \mathrm{~km})$ & 1.45 & $0.03^{* *}$ & 0.30 & 0.52 \\
\hline Moved in with partner & 0.96 & $0.01 * * *$ & 0.19 & 0.54 \\
\hline Occurring pregnancy between wave 1 and 3 & -1.26 & $0.00 * * *$ & -1.21 & $0.00 * * *$ \\
\hline \multicolumn{5}{|l|}{ Time-constant variables } \\
\hline High occupational status of partner & 1.10 & $0.00 * * *$ & -0.34 & 0.16 \\
\hline Living in West Germany & 0.21 & 0.50 & 0.60 & $0.02 * *$ \\
\hline Older age group & -0.93 & $0.00 * * *$ & -0.67 & $0.00 * * *$ \\
\hline Salience of childbirth in wave 1 & -0.14 & $0.03 * *$ & -0.18 & $0.00 * * *$ \\
\hline Constant & 2.07 & $0.00 * * *$ & 1.39 & $0.01 * * *$ \\
\hline Number of cases & 209.00 & & 260.00 & \\
\hline $\operatorname{LR} \operatorname{chi}^{2}(14)$ & 92.38 & & 91.45 & \\
\hline Pseudo $\mathrm{R}^{2}$ & 0.34 & & 0.28 & \\
\hline
\end{tabular}

*** sig. at level 0,$01 ;{ }^{* *}$ sig. at level 0,$05 ;{ }^{*}$ sig. at level 0,10

Source: pairfam, waves 1 and 3

At first sight, the significant positive effect of continuous commuting between the wave 1 and 3 might be surprising. It means that in this group, compared to the reference category, the intention to have a child becomes more important as time goes by, after having been delayed before. This is another indication that the resource argument might have a relevance for the commencement of the consideration to have a child. For men, no noteworthy effects of commuting were found.

A change in the employment status showed no additional effects on the fertility intention, neither for men not for women. Residential mobility between wave 1 and wave 3 is positively correlated with the development of the intention to have a child. For women, these effects are not significant. Again, the question of causality arises. 
Does an intention motivate residential mobility, or is it the other way round? An answer to this question needs a more precise modelling of the relationship, which has not been pursued in this study. Finally, a pregnancy which occurred between the two waves encourages the dismissal of further fertility intentions, as the desired child has already been realised in the meantime.

The coefficients of the time-constant variables in this model are to be interpreted as interaction effects with time. A high occupational status of partners of male respondents results in a higher fertility intention in the third wave. This can be interpreted as a delaying effect. The same is true for the West-effect in women, which is considerably smaller for men. For men and women, the effects of age and the salience to have a child on the fertility intention become smaller in the third wave. The latter is comprehensible, as the salience could have changed between the waves for various reasons. The negative effect of being a member of the older age group means that the giving up of a fertility intention among these respondents becomes more and more probable as time goes by. Descriptive analyses support this. The discrepancy between the two age groups increases over time.

\section{Third hypotheses}

Finally, we analysed the interrelationship between commuting behaviour and the realisation of a fertility intention, which was stated in wave 1, between wave 1 and 3 . We argued that the probability of the realisation should be negatively correlated with the time used for commuting. Commuting behaviour, the employment status - again including non-employment - and residential mobility were included in the model as time-dependent covariates. The model estimates are presented in table 6 .

In contrast to the model of changes in the fertility intention (table 5), we found significant negative correlations between time-consuming mobility arrangements (commencement of or continuous medium-/long-distance commuting) and the probability of becoming pregnant. Only when women discontinue medium-/longdistance commuting, one obtains a positive coefficient, which is not significant, however. This means that women who commute over these distances and who had intended to have a child within the next two years in the first wave postponed the realisation, at least for the time being. In contrast to the intention, the realisation of a pregnancy is strongly hindered by the demands of commuting. Interestingly enough, we found a similar effect for the commencement of medium-/long-distance commuting among men. The coefficient is significant. However, we will come back to that later.

When full-time or self-employment is interrupted or not existent at all, it has a negative effect on the realisation of a pregnancy (of the partner), but this is only found to be significant for men. Hence, it reinforces the well-known finding in fertility research that the economic or financial security is perceived as a prerequisite for having a(nother) child. We can also replicate evidence from the literature that a short-distance move is positively correlated with the realisation of a pregnancy - the 
Tab. 6: $\quad$ Probit-regression on the probability of a pregnancy between wave 1 and 3 (Heckman-selection model)

\begin{tabular}{|c|c|c|c|c|}
\hline & \multicolumn{2}{|c|}{ Men } & \multicolumn{2}{|c|}{ Women } \\
\hline & Coeff. & Sig.-Lev. & Coeff. & Sig.-Lev. \\
\hline \multicolumn{5}{|l|}{$\begin{array}{l}\text { DV: Respondent/Partner of respondent becoming } \\
\text { pregnant }\end{array}$} \\
\hline \multicolumn{5}{|l|}{ Time dependent variables } \\
\hline $\begin{array}{l}\text { Commencement of medium-/long-distance } \\
\text { commuting }\end{array}$ & -1.63 & $0.00^{* * *}$ & -1.38 & $0.00^{* * *}$ \\
\hline Constantly commuting medium-/long-distance & -0.16 & 0.17 & -0.63 & $0.02 * *$ \\
\hline $\begin{array}{l}\text { Medium-/long-distance commuting ended } \\
\text { (Ref.: Continuous/y short distance) }\end{array}$ & -0.13 & 0.55 & 0.11 & 0.67 \\
\hline Switch from full-time to non-employment & & & -0.81 & 0.18 \\
\hline $\begin{array}{l}\text { Switch from full-time to part-time employment } \\
\text { Part-time employment unchanged or switch from }\end{array}$ & -0.95 & $0.00^{* * *}$ & -0.42 & 0.31 \\
\hline $\begin{array}{l}\text { non-to part-time employment } \\
\text { Constantly non-employed or switch from part-time }\end{array}$ & & & -0.02 & 0.90 \\
\hline $\begin{array}{l}\text { Constantly non-employed or switch from part-time } \\
\text { to non-employment } \\
\text { (Ref.: Switch to or continuously full-time/self- } \\
\quad \text { employed) }\end{array}$ & & & -0.03 & 0.88 \\
\hline Short-distance move $(<50 \mathrm{~km})$ & 0.41 & $0.08^{*}$ & 0.36 & $0.09 *$ \\
\hline Long-distance move ( $\geq 50 \mathrm{~km}$ ) & 0.72 & 0.22 & 0.41 & 0.30 \\
\hline \multicolumn{5}{|l|}{ Time-constant variables } \\
\hline No child in wave 1 & -0.65 & 0.29 & 0.37 & 0.59 \\
\hline $\begin{array}{l}\text { One child in wave } 1 \\
\text { (Ref.: more than one child) }\end{array}$ & -0.37 & 0.48 & 0.53 & 0.25 \\
\hline (Technical) university degree & 0.09 & 0.62 & 0.06 & 0.70 \\
\hline Cohabiting & -0.31 & 0.22 & 0.73 & $0.00^{* * *}$ \\
\hline High occupational status of partner & -0.08 & 0.79 & 0.34 & $0.06^{*}$ \\
\hline Older age group & -0.05 & 0.77 & -0.45 & 0.12 \\
\hline Living in West Germany & -0.08 & 0.66 & 0.06 & 0.72 \\
\hline Salience of childbirth & 0.04 & 0.74 & 0.04 & 0.78 \\
\hline Constant & 0.65 & 0.64 & -0.68 & 0.51 \\
\hline \multicolumn{5}{|l|}{ AV: Intention yes in wave 1} \\
\hline No child in wave 1 & 1.25 & $0.00 * * *$ & 1.10 & $0.00 * * *$ \\
\hline $\begin{array}{l}\text { One child in wave } 1 \\
\text { (Ref:. more than one child) }\end{array}$ & 0.95 & $0.00^{* * *}$ & 0.71 & $0.00^{* * *}$ \\
\hline High occupational status of partner & -0.31 & $0.08^{*}$ & -025 & $0.01^{* * *}$ \\
\hline Older age group & -0.13 & 0.23 & -0.57 & $0.00^{* * *}$ \\
\hline Cohabiting & 0.22 & 0.14 & 0.06 & 0.64 \\
\hline Salience of childbirth & 0.32 & $0.00 * * *$ & 0.25 & $0.00 * * *$ \\
\hline Constant & -1.60 & $0.00^{* * *}$ & -0.31 & 0.27 \\
\hline Number of cases & 303 & & 376 & \\
\hline $\operatorname{LR} \operatorname{chi}^{2}(14 / 16)$ & 27.04 & 0.01 & 56.67 & 0.00 \\
\hline $\begin{array}{l}\text { LR test of rho21 }=0 \\
\operatorname{chi}^{2}(1)\end{array}$ & 0.03 & 0.86 & 0.11 & 0.74 \\
\hline
\end{tabular}

${ }^{* * *}$ sig. at level 0,$01 ;{ }^{* *}$ sig. at level 0,$05 ;{ }^{*}$ sig. at level 0,10

Source: pairfam, waves 1 and 3 
direction of causality is unclear, though. Cohabiting and a high occupational status of the partner also show significant coefficients in the case of female respondents.

As mentioned already, we estimated a Heckman-selection model, because only men and women who reported a fertility intention in the first wave were included in the analysis. In the selection equation, we considered independent variables, which were relevant for the estimation of the fertility intention in the first model displayed in table 4. These factors show the effects already known. The error terms of the main and the selection equation do not correlate significantly with each other, though.

\section{$6 \quad$ Summary and Conclusions}

The relationship between commuting behaviour and processes of family formation as well as extension has not been extensively analysed in previous research so far. Especially two deficits can be identified. Firstly, prospective longitudinal studies are missing, which would allow analysing fertility intentions as they depend on time-dependent covariates. Secondly, a distinction between fertility intention and its realisation has rarely been made before. The aim of this article is to tackle these two points and thus add considerably to the current state of research. We focused on three research questions: How are fertility intentions correlated with commuting behaviour? Do changes in commuting behaviour lead to a change in fertility intentions? Do they also have an effect on the probability of the realisation of intended fertility?

Our analyses provide evidence that commuting behaviour is only very weakly related to fertility intentions. However, the negative correlation between childlessness and commuting distance known from the literature can be replicated for women. Therefore, a remarkable difference between intention and realisation becomes apparent.

In the cross-sectional model, contrary to our expectations, we did not find a negative correlation between commuting distance and the intention to have a child within the next two years, neither for men nor for women. The question of the compatibility of work and motherhood might not be as relevant at this point in the fertility-related decision process as we had assumed. And the resource argument could to be given more weight - as least at the point of the commencement of an intention. In addition, the negative effect of commuting distance on childlessness could have been overestimated in the model, because in the cross-sectional analysis we could not control the effect of childlessness on commuting behaviour.

In the difference model, we found that women who continuously commute show a shift towards a fertility intention with a significantly higher probability. No effects could be found among men. More clearly than the cross-sectional analysis, the results of this model support the idea that intentions might be affected by economic resources to a higher degree than we expected.

In the last model, the relevance of commuting for the realisation of a fertility intention was analysed. For women, high commuting demands considerably affect the probability of a pregnancy. In contrast to previous evidence, a similar effect 
shows up among men who started medium- or long-distance commuting. Might this be a biographical transition, in which at least for a certain period of time men consider the additional duty of fatherhood as not reasonable? However, one should assume that this is just a short-term effect and not a matter of a compatibility problem for men, because continuous commuting between wave 1 and 3 does not have any notable effect.

From the substantive point of view, the article emphasises the importance of a more detailed modelling of decision processes and the separate consideration of intentions and behaviour. In regard to fertility, we have been able to show interesting and systematic differences in the effects of other behavioural variables on these two aspects. From a methodological point of view, our findings and the comparison between the results of the cross-sectional and the longitudinal models show the relevance of time-varying panel data. In the difference model, we could exclude the potentially biasing influences of time-constant unobserved heterogeneity. Therefore, we could test statements regarding a causal relationship between commuting behaviour and fertility in a more proper way. Certain issues of causality must be left open, though. This applies, for example, to the interrelationship between changing fertility intentions and shifts in the commuting behaviour. In future research, one could also have a closer look at the connection between residential mobility, commuting arrangements, and family development, using the data we used in this study.

\section{References}

Abraham, Martin; Auspurg, Katrin; Hinz, Thomas 2010: Migration Decisions Within Dual-Earner Partnerships: A Test of Bargaining Theory. In: Journal of Marriage and Family 72: 876-892 [doi: 10.1111/j.1741-3737.2010.00736.x].

Ajzen, Icek; Fishbein, Martin 2005: The Influence of Attitudes on Behavior. In: Albarracín, Dolores; Johnson, Blair T.; Zanna, Mark P. (Eds.): The Handbook of Attitudes. New Jersey: Lawrence Elrbaum: 173-223.

Allison, Paul D. 2009: Fixed Effects Regression Models. Thousend Oaks: Sage.

Bernardi, Laura; Keim, Sylvia; von der Lippe, Holger 2007: Social Influences on fertility: A comparative mixed methods study in Eastern and Western Germany. In: Journal of Mixed Methods Research 1: 23-47 [doi: 10.1177/2345678906292238].

Billary, Francesco, C.; Philipov, Dimiter; Testa, Maria 2009: Attitudes, norms and perceived behavioural control: Explaining fertility intentions in Bulgaria. In: European Journal of Population 25: 439-465 [doi: 10.1007/s10680-009-9187-9].

Brandstädter, Jochen 2001: Entwicklung, Intentionalität, Handeln. Stuttgart: Kohlhammer Verlag.

Brüderl, Josef et al. 2010: pairfam Data Manual, Wave 1. Mannheim

Buhr, Petra; Huinink, Johannes; Boehnke, Mandy; Maul, Katharina 2011: Kinder oder keine? Institutionelle Rahmenbedingungen und biographische Voraussetzungen für die Familiengründung und -erweiterung in Ost- und Westdeutschland. In: Brüderl, Josef; Castiglioni, Laura; Schumann, Nina (Eds.): Partnerschaft, Fertilität und intergenerationale Beziehungen. Würzburg: Ergon Verlag: 175-203. 
Cappellari, Laurenzo; Jenkins, Stephen P. 2003: Multivariate probit regression using simulated maximum likelihood. The Stata Journal 3: 278-294 [doi: 10.1016/0304-4076(93)90049-B].

Clark, William A. V.; Davies Wizers, Susanne 2007: Family Migration and Mobility Sequences in the United States: Spatial Mobility in the Context of the Life Course. In: Demographic Research 17,20: 591-622.

Courgeau, Danie/ 1985: Interaction between spatial mobility, family and career life-cycle: a French survey. In: European Sociological Review 1,2: 139-162.

Courgeau, Danie/ 1990: Migration, family, and career: A life course approach. In: Baltes, Paul B.; Featherman, David L.; Lerner, Richard M. (Eds.): Life-span development and Behaviour. Hillsdale, NJ: Lawrence Erlbaum: 219-255.

Davies Wizers, Susanne 1998: Linking household transitions and housing transitions: a longitudinal analysis of renters. In: Environment and Planning A 30: 615-630 [doi: 10.1068/a300615].

Dommermuth, Lars; Klobas, Jane; Lappegard, Trude 2011: Now or later? The Theory of Planned Behavior and timing of fertility intentions. In: Advances of the Life Course Research 16: 42-53.

Dubin, Jeffrey A.; Rivers, Douglas 1990: Selection Bias in Linear Regression, Logit and Probit Models. In: Sociological Methods and Research 18: 360-390 [doi: 10.1177/0049124189018002006].

Feijten, Peteke; Mulder, Clara H. 2002: The timing of household events and housing events in the Netherlands: a longitudinal perspective. In: Housing Studies 17,5: 773-792 [doi: 10.1080/026730302200000980 8].

Geis/er, Esther; Kreyenfeld, Michaela 2006: Müttererwerbstätigkeit in Ost- und Westdeutschland. In: Zeitschrift für Familienforschung 18,3: 333-360.

Grau, Andreas 2009: Pendler: Die Mehrheit nimmt weiter das Auto. STATMagazin: Wiesbaden: Destatis.

Green, Anne E.; Canny, Angela 2003: Geographical Mobility: Family Impacts. Bristol: Policy Press.

Heckhausen, Heinz 2003: Motivation und Handeln. Berlin: Springer Verlag.

Hervitz, Hugo M. 1985: Selectivity, Adaptation, or Disruption? A Comparison of Alternative Hypotheses on the Effects of Migration on Fertility: The Case of Brazil. In: International Migration Review 19,2: 293-317.

Huinink, Johannes et al. 2011: Panel Analysis of Intimate Relationships and Family Dynamics (pairfam) - Conceptual Framework and Design. In: Zeitschrift für Familienforschung 23,1: 77-101.

Huinink, Johannes; Feldhaus, Michael 2009: Family Research from the Life Course Perspective. In: International Sociology 24,3: 299-324 [doi: 10.1177/0268580909102910].

Huinink, Johannes; Schröder, Torsten 2008: Skizzen zu einer Theorie des Lebensverlaufs. In: Diekmann, Andreas; Eichner, Klaus; Schmid, Peter; Voss, Thomas (Eds.): Rational Choice: Theoretische Analysen und empirische Resultate. Wiesbaden: VS Verlag für Sozialwissenschaften: 291-308.

Huinink, Johannes; Wagner, Michael 1989: Regionale Lebensbedingungen, Migration und Familienbildung. In: Kölner Zeitschrift für Soziologie und Sozialpsychologie 41,4: 669-689.

Kalter, Frank 1994: Pendeln statt Migration. In: Zeitschrift für Soziologie 23,6: 460-476. 
Kley, Stefanie 2010: Multilokalität als Strategie zur Nutzung von Chancen. In: Soeffner, Hans-Georg (Eds.): Unsichere Zeiten: Herausforderungen und gesellschaftliche Transformationen. Wiesbaden: VS Verlag: CD-Rom Veröffentlichung.

Kulu, Hill 2005: Migration and Fertility: Competing Hypotheses Re-examined. In: European Journal of Population 21,1: 51-87 [doi: 10.1007/s10680-005-3581-8]

Kulu, Hill 2006: Fertility of Internal Migrants: Comparison between Austria and Poland. In: Population Space and Place 12,3: 147-170 [doi: 10.1002/psp.406].

Kulu, Hill 2008: Fertility and spatial mobility in the life course: evidence from Austria. In: Environment and Planning A, 40,3: 632-652 [doi: 10.1068/a3914].

Kulu, Hill; Boyle, Paul J. 2009: High Fertility in City Suburbs: Compositional or Contextual Effects? In: European Journal of Population 25,2: 157-174 [doi:10.1007/ s10680-008-9163-9].

Kulu, Hill; Boyle, Paul B.; Andersen, Gunnar 2009: High suburban fertility: Evidence from four Northern European countries. In: Demographic Research 21,31: 915-944.

Kulu, Hill; Milewski, Nadja 2007: Family change and migration in the life course: An introduction. In: Demographic Research 17,19: 567-590

Kulu, Hill; Vikat, Andres 2007: Fertility differences by housing type: an effect of housing conditions or of selective moves? In: Demographic Research 17: 775-802.

Kulu, Hill; Vikat, Andres; Andersen, Gunnar 2007: Settlement size and fertility in the Nordic countries. In: Population Studies 51,3: 265-285 [doi: 10.1080/00324720701571749].

Limmer, Ruth; Schneider, Norbert F. 2008: Studying Job-Related Spatial Mobility in Europe. In: Schneider, Norbert F.; Meil, Gerardo (Eds.): Mobile Living Across Europe I. Relevance and Diversity of Job-Related Spatial Mobility in Six European Countries. Opladen/Farmington Hills: Barbara Budrich Publishers: 13-46.

Lindenberg, Sigwart; Frey, Bruno 1993: Alternatives, frames, and relative prices: a broader view of rational choice. In: Acta Sociologica 36: 191-205 [doi: 10.1177/000169939303600304].

Mayer, Karl Ulrich 1990: Lebensverläufe und sozialer Wandel - Anmerkungen zu einem Forschungsprogramm. In: Mayer, Karl Ulrich (Eds.): Lebensverläufe und sozialer Wandel. In: Kölner Zeitschrift für Soziologie und Sozialpsychologie, Sonderheft 31: 7-21.

Maul, Katharina; Huinink, Johannes; Schröder, Torsten 2010: Elternschaftsentscheidungen im Spannungsfeld beruflicher und familiärer Planungen. In: Walper, Sabine; Wendt, Eva-Verena (Eds.): Partnerschaften und die Beziehungen zu Eltern und Kindern. Würzburg: Ergon Verlag: 215-241.

Meil, Gerardo 2010a: Geographic Job Mobility and Parenthood Decisions. In: Zeitschrift für Familienforschung 22,2: 171-195.

Meil, Gerardo 2010b: Job Mobility and Family Life. In: Schneider, Norbert; Collet, Beate (Eds.): Mobile Living Across Europe II. Causes and Consequences of Job-Related Spatial Mobility in Cross-National Comparison. Opladen: Barbara Budrich Publishers: 215-235.

Mulder, Clara H.; Wagner, Michael 2001: The connection between family formation and first-time home ownership in the context of West Germany and the Netherlands. In: European Journal of Population 17,2: 137-164 [doi:10.1023/A:1010706308868].

Nauck, Bernhard; Brüderl, Josef; Huinink, Johannes; Walper, Sabine 2012: Beziehungs- und Familienpanel (pairfam). GESIS Datenarchiv. Köln. ZA5678 Datenfile Version 3.0.0 [doi: 10.4232/pairfam.5678.3.0.0]. 
Pailhé Ariane 2009: Work-family balance and childbearing intentions in France, Germany and the Russian Federation. In: UNECE (Eds.): How generations and gender shape demographic change. Towards Policies Based on Better Knowledge. United Nations/ Geneva.

Philipov, Dimiter; Speder, Zsolt; Billari, Francesco C. 2006: Soon, Later, or Ever? The Impact of Anomie and Social Capital on Fertiltiy Intentions in Bulgaria and Hungary. In: Population Studies 60: 289-308 [doi: 10.1080/00324720600896080].

Quesnel-Vallée, Amelie; Morgan, Philip S. 2003: Missing the target? Correspondence of fertility intentions and behavior in the U.S. In: Population Research and Policy Review 22: 497-525 [doi: 10.1023/B:POPU.0000021074.33415.c1].

Rabe, Birgitta; Taylor, Mark 2010: Residential Mobility, Quality of Neighborhood and Life Course Events. In: Journal of the Royal Statistical Society A, 173,3: 531-555 [doi: 10.1111/j.1467-985X.2009.00626.x].

Reuschke, Darja 2010: Multilokales Wohnen. Wiesbaden: VS-Verlag.

Rossi, Peter H. 1955: Why families move: a study in the social psychology of urban residential mobility. Glencoe, III.: Free Press.

Rüger, Heiko; Feldhaus, Michael; Becker, Katharina; Schlegel, Monika 2011: Zirkuläre berufsbezogene Mobilität in Deutschland: Vergleichende Analysen mit zwei repräsentativen Surveys zu Formen, Verbreitung und Relevanz im Kontext der Partnerschafts- und Familienentwicklung. In: Comparative Population Studies - Zeitschrift für Bevölkerungswissenschaft 36,1 [doi: 10.4232/10.CPoS-2011-05de].

Schier, Michaela 2009: Räumliche Entgrenzung von Arbeit und Familie. Die Herstellung von Familie unter Bedingungen von Multilokalität. In: Informationen zur Raumentwicklung 1/2: 55-66.

Schneider, Norbert F. 2005: Einführung: Mobilität und Familie. Wie Globalisierung die Menschen bewegt. In: Zeitschrift für Familienforschung 17,2: 90-95.

Schneider, Norbert F.; Limmer, Ruth; Ruckdeschel, Kerstin 2002: Mobil, flexibel, gebunden. Familie und Beruf in der mobilen Gesellschaft. Frankfurt/M.: Campus.

Schneider, Norbert F.; Meil, Gerardo (Eds.) 2008: Mobile Living Across Europe I. Relevance and Diversity of Job-Related Spatial Mobility in Six European Countries. Opladen: Barbara Budrich Publishers.

Schröder, Jette; Brüderl, Josef 2008: Der Effekt der Erwerbstätigkeit von Frauen auf die Fertilität: Kausalität oder Selbstselektion? In: Zeitschrift für Soziologie 37: 117-136.

Statistisches Bundesamt 2005: Leben und Arbeiten in Deutschland. Wiesbaden.

Stutzer, Alois; Frey, Bruno S. 2007: Commuting and life satisfaction in Germany. In: Informationen zur Raumentwicklung 2/3: 179-189.

Strohmeier, Klaus P. 1989: „Movers“ and "Stayers“. Räumliche Mobilität und Familienentwicklung. In: Herlth, Alois; Strohmeier, Klaus P. (Eds.): Lebenslauf und Familienentwicklung. Opladen: Leske+Budrich: 165-188.

Wagner, Michae/ 1989: Räumliche Mobilität im Lebensverlauf: Eine empirische Untersuchung sozialer Bedingungen der Migration. Stuttgart: Enke Verlag.

Wengler, Annelene; Trappe, Heike; Schmitt, Christian 2008: Partnerschaftliche Arbeitsteilung und Elternschaft. Analysen zur Aufteilung von Hausarbeit und Elternaufgaben auf Basis des Generations and Gender Survey. Materialien zur Bevölkerungswissenschaft 127. Bundesinstitut für Bevölkerungsforschung. Wiesbaden.

Wiethölter, Doris; Bogai, Dieter; Carstensen, Janette 2009: Pendlerbericht BerlinBrandenburg 2009. In: IAB-Regional 3/2010. 
Translated from the original text by the authors, for information only. The reviewed and author's authorised original article in German is available under the title "Fertilität und Pendelmobilität in Deutschland", DOI 10.4232/10.CPoS-2012-05de or URN urn:nbn:de:bib-cpos-2012-05de8, at http:// wWw.comparativepopulationstudies.de.

Date of submission: 25.10 .2011

Date of Acceptance: 22.02.2012

Prof. Dr. Johannes Huinink ( $\varangle)$, Dr. Michael Feldhaus. Universität Bremen, Institut für empirische und angewandte Soziologie (EMPAS), Bremen, Germany.

E-Mail: huinink@empas.uni-bremen.de,feldhaus@empas.uni-bremen.de URL: http://www.soziologie.uni-bremen.de 


\section{Comparative Population Studies - Zeitschrift für Bevölkerungswissenschaft}

wWw.comparativepopulationstudies.de

ISSN: 1869-8980 (Print) - 1869-8999 (Internet)

Published by / Herausgegeben von

Prof. Dr. Norbert F. Schneider

Federal Institute for Population Research

D-65180 Wiesbaden / Germany

Managing Editor /

Verantwortlicher Redakteur

Frank Swiaczny

Editorial Assistant /

Redaktionsassistenz

Katrin Schiefer

Language \& Copy Editor (English) /

Lektorat \& Übersetzungen (englisch)

Amelie Franke

Copy Editor (German) /

Lektorat (deutsch)

Dr. Evelyn Grünheid

\section{Layout / Satz}

Beatriz Feiler-Fuchs

E-mail: cpos@bib.bund.de

\author{
Scientific Advisory Board / \\ Wissenschaftlicher Beirat \\ Jürgen Dorbritz (Wiesbaden) \\ Paul Gans (Mannheim) \\ Johannes Huinink (Bremen) \\ Marc Luy (Wien) \\ Clara H. Mulder (Groningen) \\ Notburga Ott (Bochum) \\ Peter Preisendörfer (Mainz)
}

\section{Board of Reviewers / Gutachterbeirat} Martin Abraham (Erlangen) Laura Bernardi (Lausanne) Hansjörg Bucher (Bonn) Claudia Diehl (Göttingen) Andreas Diekmann (Zürich) Gabriele Doblhammer-Reiter (Rostock) Henriette Engelhardt-Wölfler (Bamberg) E.-Jürgen Flöthmann (Bielefeld) Alexia Fürnkranz-Prskawetz (Wien) Beat Fux (Zürich) Joshua Goldstein (Rostock) Karsten Hank (Köln) Sonja Haug (Regensburg) Franz-Josef Kemper (Berlin) † Michaela Kreyenfeld (Rostock) Aart C. Liefbroer (Den Haag) Kurt Lüscher (Konstanz) Dimiter Philipov (Wien) Tomáš Sobotka (Wien) Heike Trappe (Rostock) 